\title{
DE POTÊNCIAS PERTURBADORAS: ENCONTRANDO O SAGRADO NA MODERNIDADE
}

\section{Emerson Giumbelli ${ }^{I}$}

É fácil desconfiar de um texto a propósito do sagrado cujo autor declara, logo de início, repetindo-o ao final, querer falar sobre si. De fato, Leiris nos relata lembranças sobre sua infância, o que poderia reforçar o subjetivismo (no pior sentido) da sua perspectiva. Contudo, uma possibilidade de leitura mais interessante e mais justa com o autor deveria começar lembrando que se trata de uma peça pós-freudiana. O emprego que faço desse termo enfatiza os efeitos deixados por Freud em elaboraçóes que tomam a psique como campo de exploração. A visão de Freud sobre a mente humana apostava na possibilidade de encontrar paralelos entre processos subjetivos e processos históricos. Totem e Tabu talvez seja o exemplo mais conhecido dessa aposta (Freud, 2013). E é certamente um dos textos em que o diálogo de Freud com a antropologia e a sociologia de sua época vai mais longe. Assim, o "subjetivismo" de Leiris é melhor compreendido como parte de um jogo que consiste em falar (também) de outra coisa quando se fala de si.

É evidente nessa operação o papel crucial da noção de sagrado. Não por acaso, essa noção ocupa lugar também central no diálogo de Freud com a antropologia. Freud era um leitor de Durkheim, ambos interessados que estavam no que a vida dos povos aborígenes australianos poderia nos dizer sobre a psique humana ou a sociedade em geral (Jones, 1981). É a essa tradição que remete o texto de Leiris, quando recorre à oposição entre sagrado e profano. De fato, a forma de estabelecer um contraste entre sagrado e profano e - um ponto que será, na mesma época, aprofundando pelo colega Roger Caillois (2004) - a caracterização do sagrado por sua inerente ambiguidade são questóes centrais para Leiris.

1 Professor do departamento de antropologia da Universidade Federal do Rio Grande do Sul. Contato: emerson.giumbelli@yahoo.com.br 
Ocorre que Freud e Durkheim elaboraram a noçấo de sagrado tendo por referência a vida de povos remotos, em sua época considerados "primitivos". Já Leiris, quando invoca o sagrado, trata de situações que remetem à sociedade onde vive. Se ele expõe "fatos muito simples" sobre a própria infância, não se deve desconsiderar que estamos diante da análise de situaçóes que constituem a "vida cotidiana" dentro de determinada experiência social.

Eis então o primeiro ponto para o qual quero chamar a atenção: Leiris dedica-se a um exercício que se vale da ideia de sagrado para trazer à luz situaçóes encontradas em sua sociedade. Uma série de termos permeiam o texto, produzindo metaforizaçōes de acordo com as quais noçôes forjadas a propósito de povos "primitivos" são valorizadas para esclarecer experiências - e suas fabulaçóes - de uma criança "em civilização". Que termos são esses? Ídolos, templos, heróis, mitologia, ritual, mana, xamã, casa dos homens, divindades ctonianas... Com a ajuda deles, Leiris faz a descrição de objetos, lugares e usos da linguagem que participam de sua própria infância, pintando assim a civilização com as cores da vida cotidiana primitiva. Nunca será demais enfatizar o quáo inusitada essa operaçáo se afigura quando se trata da década de 1930, momento em que a antropologia se voltava exclusivamente para povos remotos (Radcliffe-Brown, 1980). Em "O sagrado na vida cotidiana”, Leiris vale-se do saber constituído a propósito desses povos para realizar a descrição da vida "civilizada".

A possibilidade de encontrar operaçáo semelhante a essa fez com que me voltasse para outro texto. É um texto de Georges Bataille (1994), colega de Leiris e de Caillois na empreitada do Collège de Sociologie, para o qual Leiris preparou "O sagrado na vida cotidiana". Seu título é "A mutilação sacrificial e a orelha cortada de Vincent Van Gogh". Ele foi publicado na revista em que também Leiris colaborara, Documents, em seu último número, no ano de 1930. Até onde sei, é um artigo pouco conhecido nas discussóes sobre a noção de sagrado, o que me motivou a fazer com ele um contraponto ao texto de Leiris. Bataille está interessado em analisar o famoso episódio em que Van Gogh decepa parte da própria orelha, em 1888. Como veremos, esse ato individual ganhará um sentido bem mais amplo e é nisso que está 
a semelhança com o que Leiris faz com suas experiências infantis. Ao destacar alguns pontos do texto de Bataille, busco localizar certas diferenças com o texto de Leiris, mas também evidenciar similaridades. Vislumbrar tais diferenças e similaridades pode ser - é o que espero - uma contribuição para percebermos o que está em jogo em "O sagrado na vida cotidiana”.

Bataille não foi o único surrealista dissidente a se interessar por Van Gogh. Há pelo menos a célebre referência de Artaud que em 1947 publicaria seu texto sobre o pintor holandês (Artaud, [s. d.]). Informaçóes acerca da fortuna crítica de Van Gogh ajudariam a situar a apropriação que sobre sua vida e obra fazem os textos de Bataille e Artaud. Mesmo sem ter acesso a tal quadro, creio ser possível afirmar que Bataille produz, em sua análise, certa antropologização de Van Gogh. Isso se contrapóe à patologização a que foi sujeita o pintor, iniciada ainda quando era vivo. Se Bataille não nega a loucura de Van Gogh, toma-a como circunstância propícia a revelar algo mais importante e menos idiossincrático. Esse algo tem a ver com o diálogo que trava com referências antropológicas. Ao contrário do texto de Leiris, o artigo de Bataille traz várias notas de pé de página, assumindo um estilo próximo do acadêmico. Sem deixar de utilizar uma linguagem rica de imagens e chegando a uma conclusão desconcertante, o texto de Bataille deixa as pistas que, por suas referências, permitem traçar relaçóes com a antropologia.

Antes de revelar suas fontes antropológicas, contudo, Bataille analisa o ato de Van Gogh juntamente com outros dois casos que igualmente envolvem o que chama de "auto-mutilação". Casos ainda mais chocantes, pois neles seus protagonistas são respectivamente um homem que corta um dedo com os próprios dentes e uma mulher que arranca seus dois olhos após tentar fazer o mesmo com as orelhas. A fonte para o primeiro caso é um artigo do qual um dos autores é A. Borel, que havia sido psicanalista de Bataille e também de Leiris. E é praticamente por livre associação - procedimento chave na psicanálise - que Bataille vai tecendo seus comentários, que permitem articular os casos do homem e da mulher ao de Van Gogh e, ao mesmo tempo, analisar alguns temas da vida e da obra do pintor holandês. 
Essas análises se constroem por uma espécie de jogo de identificações, que mobilizam a relação de Van Gogh com Gauguin (com quem convivia quando decepou a orelha) por meio de alguns dos quadros do primeiro. Nessa relação os termos são redutíveis ao par ideal/real, simbolizados mais claramente (mas não apenas, como discorrem os interessantes comentários de Bataille) nas figuras do sol e do girassol. O sol e o fogo aparecem também nos outros dois casos de auto-mutilação, e Bataille se julga autorizado a depreender disso que as mutilaçóes estão enquadradas em relaçóes que envolvem humanos e divindades. Transcrevo essa passagem essencial no argumento do autor:

As relações entre este pintor [...] e um ideal que tem o sol como forma mais fulgurante surgiriam pois análogos àqueles que os homens outrora alimentavam com os deuses, pelo menos na medida em que estes ainda lhes provocavam estupefação; normalmente, a mutilação intervinha como um sacrifício nestas relaçôes: representa a intenção de ter perfeita semelhança com um termo ideal caracterizado na mitologia, de uma maneira bastante geral, como deus solar, mediante o rasgo e o arrancar das suas próprias partes (Bataille, 1994, p. 77-78).

$\mathrm{Na}$ sequência do texto, Bataille póe-se a colecionar exemplos que invariavelmente envolvem deuses, sacrifícios e mutilações. É aí que lança mão de fontes antropológicas (um livro que integra uma coleção da American Anthropological Association, um artigo do Journal of the Royal Anthropological Institute of Great Britain and Ireland, um livro sobre povos ameríndios), que reúne com registros sobre seitas muçulmanas, relatos arqueológicos e, sobretudo, narrativas e estudos sobre mitologia clássica (grega e romana). Da circuncisão à morte, passando pelo decepamento de dedos, emoldurados por aquilo que Van Gennep (2011) chamaria de ritos de passagem, são vários os exemplos que Bataille convoca como expressão "de uma verdadeira função social” (p. 79). Vendo essa formulação, pode não soar estranho que a discussão culmine evocando - chamo a atenção para isso - as elaboraçóes de Mauss e Hubert sobre o sacrifício, originalmente publicadas em 1899 (Mauss; Hubert, 2005). Bataille concorda com esses sociólogos ao conferir importância ao "sacrifício do deus". 
Pois nesses casos não existe mais a separação entre sacrificante e vítima. Essa separação, apesar de ser comum, esconde o que o filósofo considera ser o essencial do "mecanismo sacrificial", que consiste em uma operação de identificação. E se Mauss e Hubert têm em vista os deuses que se tornam humanos, Bataille pensa sobretudo nos humanos que se tornam deuses, produzindo essa identificação exatamente pela (auto)mutilação.

A conclusão de Bataille é atroz. O sacrifício se define pela "projeção para fora de si de uma parte de si próprio" (p. 82). Para o autor, ele se torna evidente não tanto na morte, que anularia o sujeito, e sim na mutilação, que o preserva e ao mesmo tempo o deforma e o despossui. Ele revela a existência de um "impulso", consubstancial à humanidade, que Bataille expõe mobilizando metáforas visceralmente corporais: assim como há algo que nos faz comer, há algo que nos faz vomitar. Nutrir-se e destruir-se, portanto, nos definem igualmente. A “alteração radical da pessoa” é proposta por Bataille como o essencial do "mecanismo sacrificial", tendo como seu correspondente, no plano coletivo, a rejeição do que serve para identificar um grupo. Sigamos o autor em uma de suas formulaçôes finais, na qual surge a noção de sagrado, antes de um derradeiro louvor a Van Gogh por ter demonstrado em sua loucura a existência de um impulso que pode levar à mutilação:

Pelo facto de tudo que o ciclo humano rejeita ser alterado de forma realmente impressionante é que as coisas sagradas intervêm no final da operação: a vítima estatelada num charco de sangue, o dedo, o olho ou a orelha arrancados não diferem sensivelmente dos alimentos vomitados. A repugnância só é uma das formas do estupor causado por uma horrorizante erupçáo, pelo derrame de uma força que pode submergir. O sacrificante é livre - livre de chegar até esse derrame e, ao identificar-se continuamente com a vítima, livre de vomitar o seu ser como vomitou um pedaço de si próprio [...] (Bataille, 1994, p. 87)

Voltar ao texto de Leiris após essa consulta ao artigo de Bataille traz, na primeira impressão, um sentido de contraste. Pois o sagrado em Leiris não aparece com a face terrível e chocante com que ela se apresenta em Bataille. 
As experiências de que Leiris fala são literalmente familiares, náo têm a marca das fortes passagens rituais evocadas por seu amigo. O contraste é captado na formulação de Sheringham (2006, p. 111), que comenta sobre o texto de Leiris que se trata menos da sacralização do cotidiano do que da cotidianização do sagrado. Em outro plano é também um distanciamento que se constata. Enquanto Bataille apresenta e enfoca situaçôes em que nota "a necessidade que alguém sente de se atirar ou atirar qualquer coisa de si próprio para fora de si" (1994, p. 80), Leiris, ainda quando relata suas experiências, o faz mostrando como elas dependem de lugares e coisas com as quais se relaciona como objetos alheios. Mesmo a linguagem aparece na condição de objeto, expressōes e palavras funcionando para a criança praticamente como brinquedos. Além disso, esses objetos podem ser apropriados por Leiris, como ocorre com o revólver do pai herdado pelo filho. Isso coloca em jogo o próprio amadurecimento do autor, também captado em outro comentário de Sheringham (2006) sobre a parte em que a criança é corrigida no modo como fala algo, quando uma palavra é aprendida em sua "integridade": "a linguagem deixa de ser a propriedade da dupla sagrada de irmáos e se revela como pertencente a todos" (p. 114). Em suma, o sagrado é algo que se perde à medida em que alguém ganha acesso aos objetos inicialmente alheios.

Sem desconsiderar essas diferenças, gostaria contudo de sinalizar dimensóes que podem ser apreendidas quando contemplamos o que há de semelhante entre os dois textos. Um primeiro passo trata de insistir sobre a força com que Leiris apresenta a noção de sagrado. Lembremos que ele pretende transmitir a experiência sentida na passagem para um "mundo radicalmente distinto, tão diferente do mundo profano como são diferentes o fogo e a água". Bataille, ao abordar o sacrifício, sublinha a "ruptura da homogeneidade pessoal" (1994, p. 82) pela liberaçáo de "elementos heterogêneos" (p. 87). Para ambos, portanto, o sagrado evoca uma passagem radical. Na frase seguinte, Leiris usa a palavra "perturbação" e é procurando manter a cor marcante de suas emoçóes que ele descreve as experiências de sua infância. É certo que os adjetivos do texto de Bataille são mais fortes 
- "arrebatado e doloroso", "horrível", "horripilante" -, mas é precisamente como "perturbadoras" que começa a descrever as relaçôes de Van Gogh com o sol (p. 73). E as semelhanças ficam claras quando lembramos que, em seu penúltimo parágrafo, o texto de Leiris, ao fazer uma síntese de seu relato, usa as palavras "prestigioso" e "ambíguo", mas também “insólito”, "perigoso", "proibido", "secreto" e "sobrenatural". Isso permite afirmar que, ao tratar do cotidiano, Leiris pretende sim sacralizá-lo, e o efeito não deixa de ser semelhante à busca surrealista pelo maravilhoso - eventualmente perturbador e desestabilizante - na vida comum (Moraes, 2002).

Essa busca surrealista pelo maravilhoso imprime marcas no modo como Leiris descreve sua relação com os espaços que aparecem em "O Sagrado na Vida Cotidiana”, sejam os domésticos, sejam os exteriores. Um espaço que poderia ser descrito homogeneamente é colorido para marcar diferenças e distinções, desenhando uma verdadeira topografia com propriedades fractais: o banheiro em contraponto ao quarto, o matagal em contraponto ao jardim público, o hipódromo com suas encenaçóes nada falsas em contraponto ao espaço cotidiano da casa. ${ }^{2}$ Essas diferenças e distinçóes apenas são releváveis em função das relaçóes que o próprio Leiris mantém com os espaços que descreve (e percorre). Nesse sentido, o que lemos se assemelha a uma psicogeografia, termo que os situacionistas liderados por Débord criaram para rotular uma de suas propostas (Freire, 1997; Baker, 2003). Há muitos aspectos contidos nessa noção, uma delas sendo a possibilidade de ver nela uma atualização do surrealismo (Trudel, 2009), cujas experiências com objetos dialogaram com a exploração de lugares, incluindo aqueles que serviam para expor obras artísticas (Peixoto, 2016). Outro aspecto da psicografia é o imperativo da observaçáo dos espaços a partir das relaçóes mantidas com eles e estimuladas por eles.

A descrição, relativamente longa no curto texto de Leiris, da pista de corridas merece um comentário que visa retomar a importância de uma ideia de sagrado como algo que opera produzindo distanciamentos - que,

2 Leiris recorre à oposição entre direito e esquerdo para elaborar essas diferenciações. Sobre isso, na sua relação com elaboraçôes sobre a noção de sagrado, ver Jamin (1981) e Goyatá (2014). 
por sua vez, são as condiçôes de possibilidade para identificações e participaçôes. Ela é preparada pelas impressões que povoam a passagem pelo Bois de Boulogne, onde se situa o hipódromo. Zona marginal, que evocava mais perigo do que as partes dos parques públicos cujo acesso era formalmente proibido. Quando se dedica às corridas de cavalos, Leiris aborda menos o lugar do que as experiências vividas ali em companhia de seu irmão. Embora se refiram à infância, essas experiências não são necessariamente invalidadas com a maturidade. Os hipódromos continuarão sendo lugar de "prestígio" e ao mesmo tempo de "imoralidades"; o que ali ocorre continuará a poder ser interpretado como "uma espécie de parada ritual”; sobretudo, continuará a ocorrer o jogo de identificaçóes - jogo que Bataille explora à exaustão no seu texto sobre Van Gogh - que, ao separar competidores e espectadores, funciona para reuni-los. Notemos que é nesse trecho que Leiris usa expressóes que transmitem sua participação - no sentido levy-bruhliano -, rompendo com a cisão que em outros momentos predomina entre ele e os objetos: a preocupação paterna de que ele e seu irmão "pudéssemos nos tornar jogadores", a distinção com seres (os competidores) que "poderiam ser nós mesmos", a imaginação infantil de um dia se tornar jóquei ("como tantos meninos dos bairros pobres sonham tornar-se ciclistas de competição ou boxeadores"). O trecho lembra o que Bataille escrevera em 1933 sobre os jogos e os romances policiais em "A noção de despesa", para dar exemplos de instituições que desafiam explicaçôes utilitaristas e provocam identificaçóes em seus espectadores ou leitores (Bataille, 1975). E acompanha o que o próprio Leiris escreveria sobre as touradas e suas ambiguidades rituais (Leiris, 2002).

O trecho seguinte de "O sagrado na vida cotidiana” trata da linguagem. Náo pode ser por acaso que Leiris a introduza traçando uma aproximaçáo com o bordel. Sua experiência infantil com certas expressóes e palavras é melhor transmitida quando assemelhada com a impressão masculina e adulta dos cabarés noturnos, ambas caracterizadas pela "crueza deslumbrante e insólita". Nessa parte, o texto comenta certos "fatos de linguagem", notáveis uns pela estranheza ou grandiosidade das palavras, termos, expressóes, outros pelas distinçóes sutis que demandam ou propiciam. Se há coisas 
que se perdem com a maturidade, tais experiências não deixam de estar presentes na vida adulta no modo como qualquer um/a usa e percebe a linguagem. A linguagem, percebida e usada, nunca se reduz a um sistema abstrato e intelectual de signos, que se pode desconectar das experiências pessoais; assemelha-se mais um emaranhado de linhas que nos envolve e nos conecta concretamente ao mundo. Um mundo, nas palavras do texto, "onde perdemos o pé”, pois seus elementos não estão claramente distinguidos por um sistema correspondente de signos discretos, e sim sutil e confusamente tecidos por nossas experiências. Por isso Leiris confessa que erros de leitura de sua infância continuarão, "para sempre", a singularizar e colorir palavras que fazem parte de sua vida de escritor.

Sheringham (2006) conclui, com base em seus argumentos mencionados acima, que o sagrado de Leiris é muito diferente do sagrado para Bataille, Documents e o Collège de Sociologie. Concordo que Leiris desenvolve uma sensibilidade distinta ao aplicar a noção de sagrado à "vida cotidiana". E que as experiências que evoca para ilustrá-la, nesse texto, não transmitem a violência e a crueldade que Bataille busca ao tomar o sacrifício como paradigma de suas elaboraçóes sobre o sagrado. Mas parece-me que Leiris e Bataille comungam de um entendimento semelhante sobre aquela noção. Minha aposta é que cotejar "O sagrado na vida cotidiana" com o desconcertante texto sobre Van Gogh pode se afigurar em um bom caminho para percebermos as diferenças e semelhanças entre os dois escritores. Assim, em Leiris, as cores do sagrado podem variar bastante, servindo para pintar, como quer Sheringham, a dimensão das experiências subjetivas, mas também para gravar com marcas profundas a descrição de certas formas de experiência no/do mundo. Eis o que sugerem, sobretudo, suas observaçóes sobre as corridas de cavalos e sobre a linguagem. Foi a impressão que tive quando li que, para Leiris, o sagrado é "[...] algo de vertiginoso, como o salto dos cavalos a galope ou as caixas de fundo falso da língua”.

Seja como se queira pensar a semelhança ou diferença entre Leiris e Bataille, não tenho dúvidas de que os textos enfocados neste comentário contribuem para os exercícios que apostam em fazer a antropologia operar sobre a sociedade que a originou. $\mathrm{O}$ que Bataille propóe em sua análise 
de Van Gogh segue uma linha maussiana, pois se trata de fazer revelar, com a ajuda dos "homens de outrora e de alhures", impulsos que se mostram universais. Ocorre que em lugar da tríade maussiana do dar-receber-retribuir, Bataille insiste no dar-se, fazendo-nos uma provocaçáo cujo rendimento ainda não foi esgotado. Já Leiris nos convida a mirar e perscrutar o cotidiano, procurando nele as marcas de um terreno acidentado, heterogêneo, marcas para cujo reconhecimento a noção de sagrado torna-se útil. Nesse caso, a antropologia - aludida nos termos-metáforas de que se vale Leiris para estruturar as descriçóes - é representada menos pelos povos a que se dedicava então e mais por uma perspectiva, relativista e minuciosa, que se aplica à "vida cotidiana" da sociedade em que se criou o escritor.

Creio que os comentários anteriores indicam claramente as conexóes entre o texto de Leiris e as elaboraçóes antropológicas, mais especificamente com os movimentos que possibilitaram que a antropologia se aplicasse à sociedade que a inventara. A história da antropologia costuma situar essa passagem nos anos 1950, ou mesmo depois. Mas o texto de Leiris chama a atenção para a existência de empreendimentos anteriores. $\mathrm{O}$ surrealismo certamente desempenhou um papel fundamental nesses empreendimentos, seja na França, como ilustra a revista Documents e a própria biografia de Leiris (Peixoto, 2011), seja na Inglaterra, onde se desenvolveu o projeto Mass Observation como proposta de uma "antropologia de nós mesmos" (Macclancy, 1995). O que estava em jogo era tanto a definição da antropologia (como disciplina ou como prática), quanto a relação que se poderia estabelecer - e questionar - entre povos distintamente posicionados considerando o marco da "civilização ocidental".

Abordando sobretudo o quadro da França, James Clifford (1998) chamou atençáo para essas conexóes entre o surrealismo e a antropologia. Creio que podemos avançar pelo menos em dois pontos, com a ajuda das contribuiçóes de outros textos, em especial os de Fernanda Peixoto $(2015,2016)$. Primeiro, seria interessante produzir leituras que não estejam vinculadas ao pós-modernismo antropológico, marca das elaboraçóes de Clifford. O trabalho de Julia Goyatá (2016) já lança pistas nessa direção. 
Segundo, há personagens, textos, iniciativas e episódios que merecem ser explorados nessa linha de conexóes entre antropologia e surrealismo. A procura pode se fazer em países "centrais" como foram França e Inglaterra, mas também em outras terras. Como o Brasil, onde nos deparamos com as "experiências" de Flávio de Carvalho (2001) inspiradas pelo surrealismo, pela psicanálise e pela antropologia. Nessas buscas, é fundamental que nos armemos com perspectivas capazes de perceber as articulaçóes possíveis entre ciências, artes e religióes (Giumbelli, 2016).

Por fim, é possível ainda encontrar conexôes entre "O sagrado na vida cotidiana" com discussóes recentes que envolvem os temas da secularização e do secularismo. Destaco o seguinte trecho no qual Leiris delimita seus interesses: "trata-se de procurar em fatos muito simples, colhidos na vida cotidiana e situados fora do âmbito do que constitui atualmente o sagrado oficial (religiáo, pátria, moral)...”. Com esse deslocamento, o autor estava apontando as potencialidades analíticas da noção de sagrado, recusando-se a restringi-las ao domínio "oficial". Sublinho, a partir disso, dois pontos. Primeiro, fica claro que sagrado e religioso não podem ser confundidos; mais do que isso, o religioso é juntado ao moral e ao político, sinalizando que entre esses sentidos pode haver mais proximidade do que estamos dispostos a admitir. Portanto, a secularização pode não depender ou empreender uma redução do sagrado, mas, distintamente, um deslocamento do que é sacralizado, da religião em direção à moral e à política. Segundo, os fatos da vida cotidiana não deixam de ter alguma conexão com o que Leiris chama de "oficial". O caso dos monumentos deixa isso evidente: erigidos para celebrar algo no domínio do religioso, do moral ou do político, passam a interagir com transeuntes no seu dia-a-dia. A vida social dos monumentos coloca portanto em jogo relaçóes possíveis entre o oficial e o cotidiano.

Esses dois últimos comentários não seriam possíveis, em meu caso, sem o conhecimento de textos de M. Taussig $(1997,1999)$, o que é em si mesmo uma demonstração de relaçóes factíveis entre Leiris e a teoria antropológica contemporânea. Taussig propóe que a modernidade não seja vista simplesmente 
como rompimento com a religiáo; o mais importante seria perceber nisso uma espécie de sacrilégio, ou seja, uma disputa de sacralizaçóes, em que, por exemplo, o sagrado político entra em confronto com o sagrado religioso. No entanto, a presença desses sagrados modernos às vezes só fica evidente em episódios de profanação: é o ataque a um monumento que ativa suas potencialidades como objeto de atração e identificação. Finalmente, lembro que é Taussig que, no livro que dedica às tensôes entre cromofobia e cromofilia, tocando em a assuntos tão diversos quanto o colonialismo, a antropologia e a literatura de Marcel Proust, táo cotidianos quanto tecidos, corantes e tintas (Taussig, 2009), leva adiante, embora não se restrinja apenas a suas memórias pessoais, a sugestão que Leiris faz na última frase de seu texto.

\section{REFERÊNCIAS}

ARTAUD, Antonin. Van Gogh. O suicidado pela sociedade. Rio de Janeiro: Achiamé, [s/d.].

BAKER, Phil. Secret City: Psychogeography and the End of London. In: KERR, Joe; GIBSON, Andrew. London from Punk to Blair. Londres: Reaktion, 2003.

BATAILLE, Georges. A Mutilação sacrificial e a orelha cortada de Van Gogh. In. In: . A Mutilação sacrificial e a orelha cortada de Van Gogh. Tradução Carlos Valente. Lisboa: Hiena, 1994.

. A Parte Maldita (precedida de "A Noção de Despesa”). Rio de Janeiro: Imago, 1975.

CAILLOIS, Roger. El Hombre y lo Sagrado. México: Fondo de Cultura Económica, 2004.

CARVALHO, Flavio de. Experiência n.2: uma possível teoria e uma experiência. Rio de Janeiro: NAU, 2001. 
CLIFFORD, James. Sobre o surrealismo etnográfico. In: A Experiência Etnográfica. Organização de J. R. Gonçalves. Rio de Janeiro: Ed. UFRJ, 1998, p. 132-178.

FREIRE, Cristina. Além dos mapas. Os monumentos no imaginário urbano contemporâneo. São Paulo: Annablume, Edições Sesc, FAPESP, 1997.

FREUD, Sigmund. Totem e Tabu. Porto Alegre: L\&PM, 2013.

GENNEP, Arnold V. Os ritos de passagem. Petrópolis: Vozes, 2011.

GIUMBELLI, Emerson. Ciência, arte, religião: conexôes, dissoluçôes. In: Fonseca, C; Rodhen, F; Machado, P; Paim, H (Org.). Antropologia da ciência e da tecnologia. Porto Alegre: Sulina, 2016, p. 35-62.

GOYATÁ, Júlia Vilaça. Georges Bataille e Michel Leiris. São Paulo: Humanitas/FAPESP, 2016.

GOYATÁ, Júlia Vilaça. Georges Bataille, Michel Leiris e a experiência do sagrado no entreguerras. Religião \& Sociedade, v. 34, p. 65-85, 2014.

JAMIN, Jean. Quand le sacré devint gauche. L'Ire des Vents, Rio de Janeiro, n. 3-4, p. 98-118, 1981.

JONES, Robert Alun. Robertson Smith, Durkheim and Sacrifice: A Historical Context for the Elementary Forms of the Religious Life. Journal of the History of the Behavioral Sciences, v. 17, n. 2, p. 184-205, 1981.

LEIRIS, Michel. Espelho da Tauromaquia. São Paulo: Cosac Naify, 2002.

MacCLANCY, Jeremy. Brief Encounter: The Meeting, in Mass-Observation, of British Surrealism and Popular Anthropology. The Journal of the Royal Anthropological Institute, v. 1, n. 3, p. 495-512, 1995.

MAUSS, Marcel; HUBERT, Henri. Sobre o Sacrifício. São Paulo: Cosac Naify, 2005.

MORAES, Eliane Robert. O Corpo Impossivel. São Paulo: Iluminuras/ FAPESP, 2002. 
PEIXOTO, Fernanda A. A viagem como vocação. Itinerários, parcerias e formas de conhecimento. São Paulo: Editora da Universidade de São Paulo, 2015.

PEIXOTO, Fernanda A. O olho do etnógrafo. Sociologia \& Antropologia, v. 1, p. 195-215, 2011.

PEIXOTO, Fernanda A. Os objetos e suas artes. In: FONSECA, C; RODHEN, F; MACHADO, P; PAIM, H (Org.). Antropologia da ciência e da tecnologia. Porto Alegre: Sulina, 2016. p. 63-80.

RADCLIFFE-BROWN, R. A. A posição atual dos estudos antropológicos. In: ZALUAR, A. (Org.). Desvendando Máscaras Sociais. Rio de Janeiro: Francisco Alves, 1980, p. 177-194.

SHERINGHAM, Michael. Everyday Life. Theories and Practices from Surrealism to the Present. Oxford: Oxford University Press, 2006.

TAUSSIG, Michael. Transgression. TAYLOR, M. (Org.). Critical Terms for Religious Studies. Chicago: The University of Chicago Press, 1997, p. 349-364. TAUSSIG, Michael. Defacement - Public Secrecy and the Labor of the Negative. Stanford, California: Stanford University Press, 1999.

TAUSSIG, Michael. What Color Is the Sacred? Chicago: University of Chicago Press, 2009.

TRUDEL, Alexandre. Des surrealistes aux situationnistes. COnTEXTES, n. 6, set. 2009. Disponível em: <http://contextes.revues.org/4421>. Acesso em: 15 mar. 2017.

Recebido em: 10/12/2016 Aprovado em: 20/02/2017 